\title{
Covid-19 y una potencial ola proteccionista: análisis de los efectos de la pandemia y los planes de recuperación de China en el comercio exterior
}

\author{
María Margarita Vesga BenaVides ${ }^{*}$
}

\section{RESUMEN}

El presente artículo expone un breve análisis de los efectos económicos y en el comercio exterior que han tenido las regulaciones y políticas implementadas a nivel mundial para enfrentar y contener la pandemia de la covid-19, incluyendo: i) restricciones sobre las exportaciones de insumos médicos y de protección personal y facilitación de las importaciones, ii) limitaciones a la movilidad y cierres de fronteras y iii) los efectos de la incertidumbre generada por la emergencia sanitaria en la inversión extranjera directa. Adicionalmente, se propone que una de las consecuencias a largo plazo que dejará la covid-19 será el aumento generalizado de medidas proteccionistas a través de mecanismos de defensa comercial y barreras arancelarias y no arancelarias. Lo anterior en respuesta a las políticas de recuperación económica que implementen los países. Particularmente, China cuenta con un plan de reactivación de exportaciones tan agresivo que tiene el potencial de desencadenar una ola de medidas de defensa comercial en el mundo para contener su expansión en los mercados internacionales. La historia del desarrollo del comercio exterior muestra cómo el aumento en las medidas de defensa comercial ha sido una respuesta normal del mundo ante las graves crisis financieras que se han presentado. En el presente caso, ya se muestran algunos indicios de aumento del proteccionismo en algunos países, especialmente en la industria siderúrgica. Por ende, es probable que, en un contexto de recuperación de

1 Egresada de la Facultad de Derecho de la Universidad de los Andes de Colombia. Actualmente, es asociada del equipo de defensa y políticas comerciales en Araújo Ibarra Consultores Internacionales. Correo electrónico: margarita.vesga16@gmail.com

* DOI: https://doi.org/10.18601/01236458.n55.03 
la economía mundial por la covid-19, los países continúen adoptando medidas para proteger la sostenibilidad de sus industrias nacionales.

Palabras clave: defensa comercial, China, recuperación económica, comercio internacional, covid-19.

\section{COVID-19 AND A POTENTIAL PROTECTIONIST WAVE: ANALYSIS OF THE PANDEMIC EFFECTS AND CHINA'S RECOVERY PLANS ON INTERNATIONAL TRADE}

\section{ABSTRACT}

The following article presents a brief analysis of the effects on the economy and international trade of the rules and policies implemented in the world to face and contain the covid-19 pandemic, including: i) export restrictions on medical supplies and personal protective equipment, as well as import facilitation measures ${ }_{i}$ ii) travel limitations and border closures; and iii) the effects of the uncertainty generated by the sanitary emergency on foreign direct investment. In addition, the paper proposes that one of the long-term consequences of covid-19 will be a generalized increase in protectionist policies through trade remedies and tariff and non-tariff barriers, in response to the economic recovery measures implemented in each country. Particularly, China has such an aggressive exports recovery plan, that it will potentially trigger a wave of trade remedies across the globe, to contain its expansion on foreign markets. The history of international trade development demonstrates that an increase in trade remedies, has been a usual response in the world, after deep financial crisis. In this case, early signs of the increase in protectionism are already appearing in some countries, especially in the steel industry. Thus, it is probable that, in the context of a global economic recovery, countries continue to adopt measures to protect the sustainability of their national industries.

Keywords: Trade remedies, China, international trade, economic recovery, covid-19.

\section{INTRODUCCIÓN}

Desde que se reportaron los primeros casos de la enfermedad covid-19 causada por el virus SARS-CoV-2 (en adelante la covid-19) desde Wuhan, China, el 31 de diciembre de 2019, se ha especulado sobre cómo las medidas tomadas por cada país para controlar el avance de la pandemia afectarán el comercio internacional. Aunque todavía existe incertidumbre sobre el futuro, ya hay cierta información que permite obtener algunas conclusiones preliminares sobre sus efectos. 
La actual pandemia que atraviesa el mundo presenta desafíos sin precedentes que tendrán dramáticos impactos socioeconómicos en el planeta. Actualmente, la mayoría de países ya superaron las fases de preparación y control del virus y el mundo ha entrado en una fase de reactivación, en la que se busca disminuir los impactos que tuvo la emergencia sanitaria en la economía y promover la activación de los mercados.

El presente documento tiene el objetivo de presentar algunos efectos y consecuencias conocidos que tanto la pandemia de la covid-19 como las medidas que han tomado los países para afrontarla han tenido en el comercio exterior. Además, se propone que una de las consecuencias de la pandemia a largo plazo será el incremento del proteccionismo a nivel mundial, manifestado en un aumento de medidas de defensa comercial y barreras arancelarias y no arancelarias, como consecuencia de los planes de reactivación que tomarán países, como China, para ayudar a sus sectores estratégicos nacionales.

El documento está estructurado en dos partes. En la primera se hará un recuento de las principales medidas regulatorias tomadas por los países para la contención del virus y algunos de efectos a corto plazo, que ya se conocen, sobre la economía mundial. Las medidas examinadas incluyen: i) restricciones a las exportaciones de productos médicos y de protección personal, así como medidas de facilitación de sus importaciones; ii) limitaciones a la movilidad y cierres de fronteras; iii) la incertidumbre producida por el virus que genera graves impactos sobre la inversión extranjera directa.

La segunda parte contendrá una descripción de los planes de reactivación de la economía de China, que incluyen subsidios en forma de exenciones sobre impuestos, con la capacidad de distorsionar los precios de los mercados internacionales, que obligarán a varios países a tomar medidas excepcionales para garantizar la sostenibilidad de las industrias nacionales. Además, se tomará el sector siderúrgico de manufactura de acero como caso de estudio, ya que este sector contaba con una problemática anterior a la pandemia, que se vio acentuada por esta y obligó a varios países a tomar acciones rápidas para evitar el potencial daño a sus industrias nacionales. Finalmente, se analizarán algunas de las medidas que se están empezando a tomar en Colombia para proteger a las industrias nacionales y, por último, se presentarán las conclusiones.

MEDIDAS DE CONTROL DE LA COVID-19

Y SUS CONSECUENCIAS A CORTO PLAZO

\section{Medidas restrictivas de las exportaciones y facilitadoras de las importaciones}

Debido a la preocupación por escasez de productos considerados vitales para la prevención y el tratamiento de la covid-19, la mayoría de países adoptaron medidas restrictivas sobre sus exportaciones y, a su vez, otras medidas que facilitaban las importaciones de equipos médicos, medicamentos y elementos de protección personal. 
El primer país en tomar este tipo de medidas fue China, que desde inicios de febrero nacionalizó el control de la producción y distribución de insumos médicos y los limitó al uso en el mercado doméstico (U. S. Congressional Research Service, 2020). Esto implicó la suspensión de las exportaciones de importantes insumos para la industria farmacéutica mundial, lo que obligó a la paralización por varias semanas de fábricas en América del Norte, Europa y el resto de Asia que no disponían de proveedores alternativos (Comisión Económica para América Latina y el Caribe, 2020). No obstante, China controló su brote rápidamente, lo que permitió la reapertura de la manufactura y exportación de estos insumos a mediados de marzo, aunque con controles de exportación más fuertes (International Trade Centre, 2020).

Posteriormente, un total de 94 países establecieron medidas restrictivas de las exportaciones de insumos médicos, mientras que 104 países tomaron a la vez medidas de liberalización y flexibilización de las importaciones de este tipo de productos (International Trade Centre, 2020). Entre los países que decidieron imponer restricciones sobre las exportaciones de productos médicos, medicamentos y elementos de protección personal se encuentran los tres principales exportadores de estos productos: China, Alemania y Estados Unidos (World Trade Organization, 2020a).

En un inicio, la comunidad internacional temió por los potenciales efectos de estas medidas en las cadenas globales de valor y en la cooperación internacional (González, 2020). No obstante, el desarrollo de estas medidas no tuvo consecuencias graves. Actualmente, muchas de las restricciones sobre las exportaciones que fueron impuestas de forma temporal han finalizado y muchas otras se han flexibilizado.

En efecto, el impacto de las medidas restrictivas de las exportaciones no fue muy alto, pues el comercio internacional de productos médicos, importaciones y exportaciones apenas alcanzó un valor de USD 2 trillones en 2019, equivalente al 5 \% del total del comercio mundial (World Trade Organization, 2020a), sumado a que las medidas restrictivas se han ido flexibilizando con el tiempo.

Otra consecuencia que dejaron las medidas restrictivas en algunos países, particularmente en aquellos con grandes industrias farmacéuticas, como Estados Unidos, es que tomaron conciencia de su gran dependencia de China como proveedor de insumos médicos y materias primas para sus laboratorios. Por ende, el Gobierno estadounidense buscará diversificar sus proveedores en regiones más cercanas, como América Latina, e incentivar la industria nacional de estos insumos (U. S. Congressional Research Service, 2020).

Finalmente, una consecuencia positiva de la emergencia sanitaria fue la aceleración de la implementación de medidas de facilitación del comercio para agilizar la importación de los productos clave para afrontar la covid-19, a través de procedimientos virtuales que redujeron la necesidad de contacto personal, lo cual generará una importante disminución en los costos logísticos de importación (World Trade Organization, 2020b). 


\section{Cierres de fronteras y restricciones en el transporte}

Por otra parte, desde el inicio de la pandemia, las medidas que han producido el costo más alto para la economía mundial y el intercambio internacional de bienes y servicios han sido los cierres de fronteras y las restricciones de movilidad, que fueron impuestas por un gran número de países.

Respecto al comercio de bienes, según la Organización Mundial del Comercio (en adelante OMC), el comercio mundial se redujo 18,5\% en el segundo trimestre de 2020, en comparación con el mismo periodo en 2019 (World Trade Organization, 2020c), aunque la contracción fue fuerte, resultó menor a la anticipada por la OMC en abril de 2020, que proyectó en un escenario pesimista una contracción del 32 \%. En la región de Latinoamérica, las importaciones y exportaciones intrarregionales tuvieron una caída del 17 \% entre enero y mayo de 2020, en comparación con el mismo periodo de 2019 (Comisión Económica para América Latina y el Caribe, 2020).

Las restricciones en transporte y movilidad tuvieron un impacto en dicha contracción del comercio mundial de bienes. Primero, debido a la imposibilidad de viajes, la oferta de bienes que dependían de la presencia física de los proveedores se vio disminuida. Segundo, la disminución en la demanda y la creación de nuevos controles y requisitos en puerto tuvo un impacto en el transporte de carga, causando un alza de precios (World Trade Organization, 2020b).

En cuanto al comercio mundial de servicios, las restricciones a la movilidad tuvieron incluso mayores impactos en el intercambio mundial. Sin duda alguna, los sectores más afectados por la pandemia han sido el turismo y el transporte aéreo. El turismo internacional se contrajo un $22 \%$ en el primer trimestre del 2020 y podría caer hasta un $60 \%-80 \%$ en el conjunto del año, de acuerdo con la Organización Mundial del Turismo (2020). Para Latinoamérica, la paralización del turismo tendrá consecuencias graves, puesto que en 2019 representó el 48 \% del valor de sus exportaciones totales de servicios (Comisión Económica para América Latina y el Caribe, 2020).

Adicionalmente, otros servicios dependientes del movimiento de personas también sufrieron grandes impactos que han incrementado sus costos. La imposibilidad de continuar con interacciones personales tendrá un impacto en sectores como manufactura y en el mantenimiento de las cadenas globales de valor, pues muchas de estas interacciones difícilmente podrán ser reemplazadas por el contacto virtual (World Trade Organization, 2020b).

\section{La incertidumbre y sus efectos en la inversión extranjera directa}

Finalmente, otra de las consecuencias de la covid-19 en el mundo ha sido el incremento de la incertidumbre. De acuerdo con el índice mundial de incertidumbre (World 
Uncertainty Index) ${ }^{2}$, el nivel de incertidumbre causado por la covid-19 ha superado en un $60 \%$ los niveles causados por la guerra de Irak y el brote de Síndrome Respiratorio Agudo Grave (SARS, por sus siglas en inglés) (World Trade Organization, 2020b). El aumento de la incertidumbre tiene un impacto directo en los niveles de inversión extranjera directa, ya que los inversionistas no cuentan con la confianza y estabilidad necesarias para hacer grandes transacciones.

La Conferencia de las Naciones Unidas sobre Comercio y Desarrollo (UNCTAD) predijo que los niveles globales de inversión extranjera directa se contraerán entre un $30 \%$ y $40 \%$ en el periodo 2020/21 (UNCTAD, 2020). Para países en vías de desarrollo, este impacto será más fuerte. De hecho, a finales de marzo, el Fondo Monetario Internacional anunció que inversionistas retiraron USD 83 billones de países en vías de desarrollo, que es el mayor retiro de capital registrado en el mundo (Seric y Hauge, 2020).

\section{PROTECCIONISMO COMO CONSECUENCIA A LARGO PLAZO DE LAS MEDIDAS DE REACTIVACIÓN}

Por otra parte, la covid-19 traerá consecuencias económicas y de comercio exterior a largo plazo sobre las que todavía no es posible cuantificar el impacto. Una de estas consecuencias es el proteccionismo, manifestado a través de un aumento de medidas de defensa comercial y barreras arancelarias y no arancelarias que implementaran los países para mitigar los efectos de las ayudas estatales que impondrán países con grandes capacidades económicas para reactivar su economía.

China fue el primer país en sufrir los efectos de la pandemia en enero y, por ende, el primero en controlar el brote y, además, cuenta con amplias capacidades financieras para reponerse de la crisis. Precisamente, el gigante asiático ha implementado agresivos planes para la reactivación de su economía y sus sectores estratégicos que podrán distorsionar los precios del mercado y derivar en prácticas ilegales de comercio o aumentos injustificados de importaciones.

La covid-19 acentuó las dificultades en materia de sobrecapacidad y distorsión del mercado de China, por tratarse de una economía centralmente planificada, que en el pasado han sido denunciadas. Aunado a esto, debido a las restricciones a las importaciones, las empresas chinas buscarán reducir sus inventarios vía reducción de precios. Asimismo, como parte de su plan de reactivación económica, el Estado ofrece múltiples ayudas adicionales a ciertos sectores estratégicos, que generarán aún más desequilibrios con respecto a países que no cuentan con dichas posibilidades y que, además, se vieron gravemente afectados por la pandemia. Lo anterior tendrá como consecuencia un aumento en las medidas de defensa comercial.

2 El World Uncertainty Index se trata de una medición elaborada a partir del conteo de la frecuencia en la que aparecen palabras relacionadas con "incertidumbre" en los reportes por país del Economist Intelligence Unit. 


\section{Las medidas de reactivación económica tomadas por China sobre sus sectores estratégicos}

El 17 de marzo de 2020, China reactivó gran parte de sus sectores productivos, el Consejo de Estado ${ }^{3}$ chino emitió un comunicado haciendo énfasis en la importancia de la estabilización de los empleos y anunció que el gobierno agilizaría los procesos de aprobación de grandes proyectos de infraestructura (U. S. Congressional Research Service, 2020).

Además, en la misma fecha, el ministro de Finanzas de este país anunció, como parte de su paquete de ayudas a las empresas de sectores clave para la reactivación de su economía, el incremento en el reembolso del impuesto al valor agregado (IVA) sobre las exportaciones de casi 1464 productos chinos, a partir del 20 de marzo de 2020 (Deloitte, 2020).

China usa la política de reembolsos de IVA sobre las exportaciones como una política fiscal dirigida a impulsar las exportaciones de sectores determinados rápidamente, ya que reduce el IVA virtualmente a cero (U. S. Congressional Research Service, 2020). Entre los productos seleccionados, 1048 productos reciben el $13 \%$ de reembolso y 380 productos reciben el $9 \%$ (Deloitte, 2020).

La tabla 1 muestra los sectores a los que pertenecen los productos beneficiados por esta medida.

TABLA 1. REEMBOLSOS DE IVA SOBRE LAS EXPORTACIONES

DE CHINA, MARZO DE 2020 (9\%-13\%)

\begin{tabular}{|l|l|}
\hline \multicolumn{1}{|c|}{ Categoría } & \multicolumn{1}{c|}{ Ejemplos de productos incluidos } \\
\hline Ganado en pie & $\begin{array}{l}\text { Equino, bovino, porcino, cabra, oveja, pollo, pavo, } \\
\text { pato. }\end{array}$ \\
\hline $\begin{array}{l}\text { Carne (fresca, refrigerada, congelada, } \\
\text { subproductos) }\end{array}$ & Bovino, porcino, pollo, oveja. \\
\hline Lácteos & Leche y huevos. \\
\hline $\begin{array}{l}\text { Animales exóticos (vivos, congelados, } \\
\text { cuernos, garras, pieles, plumas) }\end{array}$ & $\begin{array}{l}\text { Micos, serpientes comestibles y reptiles, tortugas, } \\
\text { raptores, avestruz, paloma, castor, algalia y cuerno de } \\
\text { rinoceronte. }\end{array}$ \\
\hline $\begin{array}{l}\text { Algodón, flores, vegetales, frutas, } \\
\text { aceites, nueces, especias }\end{array}$ & Orquídeas y ajo. \\
\hline $\begin{array}{l}\text { Químicos industriales y orgánicos, } \\
\text { insecticidas }\end{array}$ & $\begin{array}{l}\text { Utilizados en pinturas, nylon, látex, caucho, } \\
\text { plásticos, soldaduras, anestesias y desinfectantes. }\end{array}$ \\
\hline
\end{tabular}

3 En China el Consejo de Estado es la autoridad administrativa máxima del gobierno central de la República Popular de la China. 


\begin{tabular}{|l|l|}
\hline \multicolumn{1}{|c|}{ Categoría } & \multicolumn{1}{c|}{ Ejemplos de productos incluidos } \\
\hline Productos dentales y de papel & $\begin{array}{l}\text { Hilo dental, papel higiénico, servilletas, toallas de } \\
\text { papel. }\end{array}$ \\
\hline Madera, Piedra, papel de lija & Cajas, tablas, ventanas, puertas. \\
\hline $\begin{array}{l}\text { Perlas, gemas, diamantes para uso } \\
\text { industrial }\end{array}$ & $\begin{array}{l}117 \text { productos de las subpartidas } 72 \text { y } 73 \text { incluyendo } \\
\text { barras, alambrón, placas, tuberías, entre otros. }\end{array}$ \\
\hline Acero y níquel & \\
\hline
\end{tabular}

Fuente: Congressional Research Service (2020).

Posteriormente, el 12 de agosto de 2020, el Gobierno chino complementó estas medidas con otras adicionales. Las nuevas políticas se enfocan en la expansión de créditos sobre la exportación e incluyen: i) la Corporación China de Créditos y Seguros extenderá el periodo de gracia de sus pagos para empresas de comercio exterior; ii) expansión de créditos de exportación a pymes; iii) asistencia financiera a empresas financiadas por extranjeros; iv) nuevos préstamos por parte del Banco de Exportaciones-Importaciones de China, y v) incremento de las inversiones por fuera de China, especialmente en las industrias tecnológicas (Inside U. S. Trade, 2020a).

Con todas estas medidas, China busca además continuar con su agresivo plan Made in Cbina 2025, el cual pretende crear ventajas competitivas para expandir sus mercados mundiales en sectores estratégicos (U. S. Congressional Research Service, 2020). Los sectores principales que China busca posicionar con su plan son:

- Tecnologías de la información.

- Maquinaria y robots computarizados.

- Aviación y viajes espaciales.

- Maquinaria para agricultura.

- Equipos energéticos.

- Nuevos materiales.

- Biofarma y equipos médicos.

- Vehículos ahorradores de energía.

- Equipos marítimos.

- Equipos de transporte y ferroviarios.

Ahora bien, los agresivos planes de China para compensar la baja en exportaciones en el primer semestre de 2020 y ganar posición en el mercado, en un contexto en el que el mundo se concentra en recuperarse de los graves efectos económicos de la covid-19, generan gran miedo en los países receptores de sus importaciones de que inunde los mercados internacionales con sus productos a precios distorsionados. La amenaza se 
vuelve evidente ante la normalización de la actividad manufacturera de China y el crecimiento de sus inventarios, al tiempo que el consumo mundial continúa reducido.

Es más, el Fondo Monetario Internacional (en adelante, FMI) prevé profundas contracciones en la actividad económica de gran cantidad de países. En Latinoamérica, el FMI pronostica una caída del -5,2 \%; para Europa del -5,2 \%; Medio Oriente y Asia Central, -2,8\% y Estados Unidos, 5,9\% (International Monetary Fund, 2020). Sin embargo, en el caso de China, pronostican un leve crecimiento del $1 \%$ (International Monetary Fund, 2020). Lo anterior puede agudizar los efectos de los planes de recuperación de China.

Aunque las consecuencias de esta situación se verán a largo plazo, ya se ve un rápido aumento de medidas proteccionistas de varios países en el sector del acero, que históricamente se ha visto gravemente afectado por las agresivas prácticas de la industria china.

América Latina, ante su alta dependencia del petróleo y los bienes de consumo, aunada a su bajo desempeño económico, puede verse especialmente afectada por las agresivas medidas tomadas por China.

\section{Caso de estudio: aumento de medidas proteccionistas en el sector de acero}

Desde hace varios años, la industria siderúrgica mundial se enfrenta al exceso de capacidad en la producción mundial de acero, en el que China es el principal actor, pues es responsable del $50 \%$ con 280 millones de toneladas, lo que equivale a 4,1 veces el consumo de acero de América Latina (Alacero, 2018).

En China, a pesar de la crisis de la covid-19, la producción de acero aumentó en un $3 \%$ en comparación con el mismo periodo en 2019 y sus inventarios aumentaron un $45 \%$ en el mismo periodo (U. S. Congressional Research Service, 2020). Bajo estas condiciones, China aumentará sus exportaciones de este sector por medio de la reducción de precios para disminuir sus inventarios. Así, se distorsionarán aún más los mercados de la industria siderúrgica, ya que los precios no obedecen a la lógica del mercado, sino que han sido afectados por las múltiples ayudas estatales a las empresas chinas.

Ante este panorama, muchos países fueron ágiles en imponer medidas de defensa comercial o incluso otro tipo de barreras arancelarias para evitar potenciales daños.

La Comunidad Europea adelantó a mayo la revisión de los aranceles de salvaguardia a las importaciones de acero, debido a los decesos en la cantidad de pedidos y los excedentes de acero a bajos precios en los mercados mundiales (Platts, 2020a). La asociación siderúrgica de Europa (EUROFER) solicitó una reducción del 75 \% de las cuotas de importación para el segundo y tercer trimestre de 2020 (Platts, 2020a).

E1 2 de junio de 2020, la Unión Europea notificó a la OMC de reformas en sus salvaguardias sobre el acero, que incluyeron la modificación de los cupos de sus contingentes arancelarios de importación vigentes y el cambió del periodo de revisión de anual a trimestral (European Commission, 2020). 
Turquía, por su parte, incrementó los aranceles de importación de productos de acero de entre $9 \%-15 \%$ a $14 \%-20 \%$ por un periodo inicial entre el 18 de abril hasta el 15 de julio que no ha sido renovado hasta el momento (Platts, 2020b).

Adicionalmente, India también se encuentra finalizando una norma en la que incrementará los aranceles y controles de importación a productos chinos que cuentan con producción nacional, entre los que se encuentran productos de la industria de acero (Srivastava, 2020).

Estados Unidos, que ya cuenta con aranceles sobre la mayoría de importaciones chinas de acero, también fortaleció sus sistemas de vigilancias ante un potencial incremento de importaciones del gigante asiático (U. S. Congressional Research Service, 2020). Además, recientemente Donald Trump reiteró su promesa de campaña de relocalizar las industrias estratégicas de vuelta a Estados Unidos, incluyendo acero, electrónicos, aeroespacial, automóviles y maquinaria, entre otros (Inside U. S. Trade, 2020b).

\section{Potencial aumento de medidas de defensa comercial para detener los agresivos planes de expansión chinos}

Los agresivos planes de expansión con los que cuenta el gigante asiático tienen al mundo preparando las reacciones adecuadas para evitar la inundación de los mercados de productos chinos a precios menores del valor normal del mercado y de los potenciales daños a las industrias nacionales.

No obstante, estos efectos todavía no se conocen y no se pueden cuantificar, puesto que i) las notificaciones de medidas de defensa comercial, como los derechos antidumping y compensatorios y cambios en los aranceles de aduanas, que cada país miembro de la OMC está obligado a hacer, son publicadas de forma anual o semestral, a excepción de las salvaguardias que se publican de inmediato y todavía no han sido publicadas $_{i}$ ii) las investigaciones toman largo tiempo en concluir, usualmente entre seis meses y un año, por lo que los rezagos proteccionistas que dejará la covid-19 en la economía mundial no se conocerán hasta 2021.

Aun así, la historia de los últimos veinte años nos demuestra que, en el mundo, después de las crisis económicas, los países responden con aumentos generalizados en las medidas de defensa comercial. La siguiente gráfica muestra las medidas de defensa comercial: salvaguardias (SVG), derechos antidumping (AD) y derechos compensatorios $(\mathrm{CV}$, por sus siglas en inglés) que se han impuesto anualmente por los miembros de la OMC, en el periodo 2000-2020.

La gráfica 1 muestra cómo las medidas de defensa comercial aumentaron en el 2000 como una reacción a la crisis financiera de los años de 1990; después de la gran recesión de 2008 también tuvieron una leve alza y luego del desplome de los precios del petróleo en 2015 se vió un incremento significativo en el siguiente año. Finalmente, en lo corrido de 2020, aunque no se encuentra disponible la información sobre investigaciones de imposición de derechos antidumping y compensatorios, ya se han 
notificado la apertura de diez investigaciones por salvaguardia y las cifras totales de las demás medidas se conocerán en el próximo año.

GRÁFICA 1. MEDIDAS DE DEFENSA COMERCIAL NOTIFICADAS A LA OMC 2000-2020 400

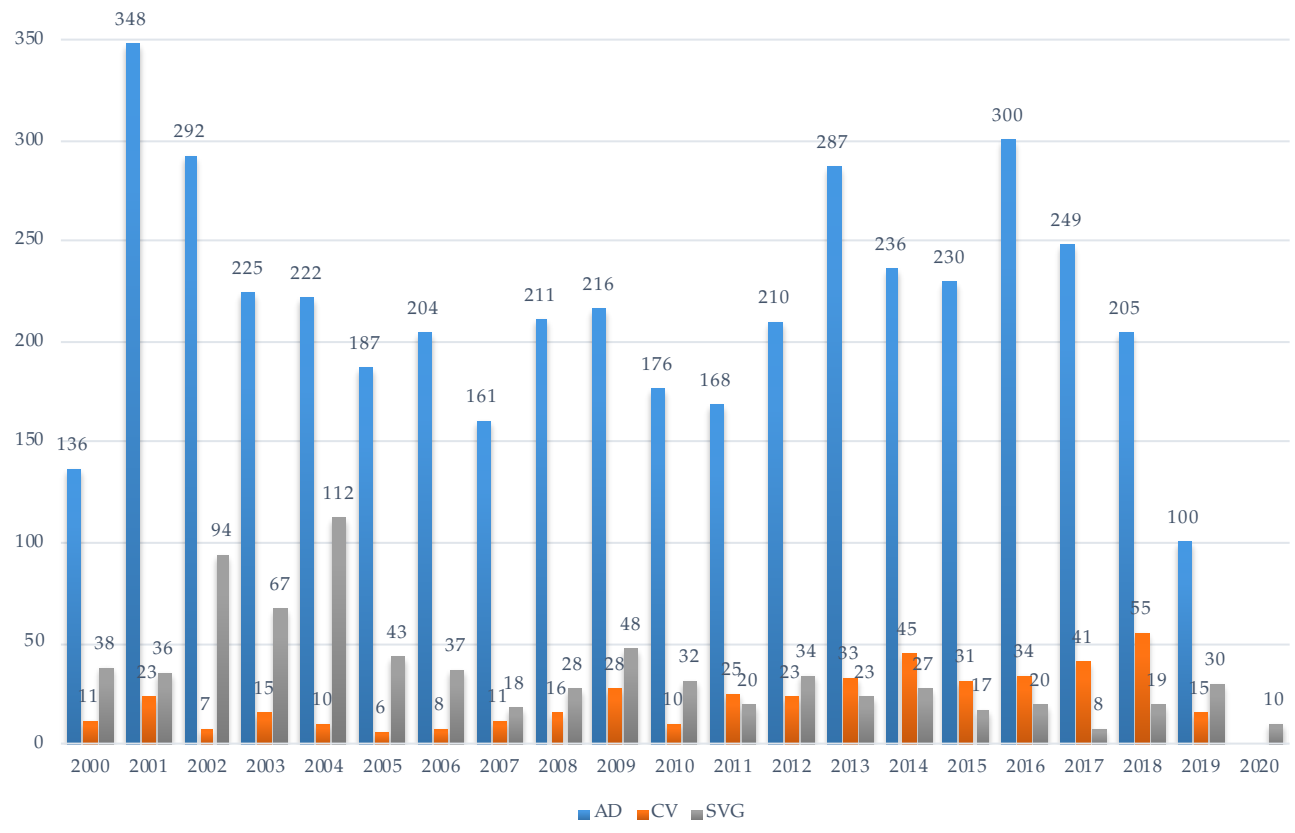

Fuente: elaboración propia con datos del WTO, Integrated Trade Intelligence Portal (I-TIP) (2020).

Así, el desarrollo histórico del comercio internacional a través de los acuerdos de la OMC demuestra que el aumento de las medidas de defensa comercial es una respuesta normal ante las profundas crisis económicas que el mundo ha atravesado.

Análisis de las medidas proteccionistas impuestas y las investigaciones iniciadas por defensa comercial en Colombia desde la llegada de la covid-19 al país

En Colombia, dentro de lo corrido del año, ya se han impuesto algunas medidas proteccionistas tomadas rápidamente con ocasión de proteger la industria nacional de los deterioros latentes de la covid-19. Un ejemplo, es el Decreto 527 de 2020 que prohibió las importaciones de etanol que fueran superiores a las necesarias para cubrir el déficit de la demanda. La prohibición inició el 7 de abril de 2020 por un periodo inicial de dos meses, que después fue prorrogado hasta el 8 de julio de 2020 (Decreto 820 de 2020). En este caso, el Gobierno colombiano justificó la imposición de esta 
medida a través de las excepciones de los artículos XI y XX del Acuerdo General sobre Aranceles Aduaneros y Comercio (GATT, por sus siglas en inglés), argumentando que la medida era necesaria para evitar un exceso de producción e inventarios que ponga en riesgo la producción de alimentos de la canasta básica alimentaria ${ }^{4}$.

Por otra parte, el país también está iniciando múltiples investigaciones para imponer medidas de defensa comercial a importaciones chinas, principalmente. De acuerdo con la información disponible las investigaciones iniciadas para la imposición de medidas de defensa comercial en Colombia se enfocan principalmente en productos de sector de construcción. Esto se sustenta en que una de las principales apuestas del Gobierno nacional para la reactivación económica pospandemia son los proyectos de construcción e infraestructura (Presidencia de la República, 2020).

De hecho, al ser un sector que contribuye de gran manera a la creación de empleo formal y a la generación de encadenamientos productivos, la inversión en infraestructura es una herramienta fiscal de política anticíclica muy importante en la reactivación de la economía, que se ha usado a escala global tras la crisis de los años de 1930, la Segunda Guerra Mundial y la recesión de 2008 (Delgado, 2020).

Esta fórmula se está usando actualmente por gran parte del mundo como apuesta para la reactivación. Por tanto, las industrias relacionadas con construcción e infraestructura serán de las más protegidas por los países a través de medidas de defensa comercial. De hecho, múltiples productos pertenecientes a estos sectores se benefician de los reembolsos de IVA sobre exportaciones de ofrecidos por China (tabla 1).

En Colombia, a la fecha el Ministerio de Comercio, Industria y Turismo, autoridad encargada de investigar y decidir sobre las solicitudes de medidas de defensa comercial, ha recibido nueve solicitudes de investigación o prórroga de derechos antidumping y una por salvaguardia. Las solicitudes han sido todas sobre productos relacionados con el sector de la construcción: tubos de acero, perfiles de acero en L y en U, baldosas de cerámica, perfiles de acero aleado y sin alear, laminas lisas galvanizadas, perfiles de aluminio, espejos sin enmarcar y láminas acrílicas (Ministerio de Comercio, Industria y Turismo, 2020). Adicionalmente, ocho de las investigaciones iniciadas han sido contra productos originarios de China (Ministerio de Comercio, Industria y Turismo, 2020).

Es probable que el mismo comportamiento que hasta ahora está empezando a surgir en Colombia, se replique en otros países y entremos a una era de proteccionismo y de contención de los planes de expansión de China.

4 En cuanto a las justificaciones mencionadas, resulta interesante analizar que las excepciones del artículo XX del GATT, en ninguno de sus literales, incluyen una situación como la pandemia por la covid-19, que permita justificar este tipo de medidas para productos diferentes a alimentos o medicamentos. En el caso del etanol, aunque se trata de un biocombustible, el Gobierno colombiano argumentó un riesgo en la producción de caña de azúcar, su principal materia prima, para imponer la medida bajo el literal (b) del artículo XX del GATT que permite las medidas "necesarias para proteger, entre otras, la salud y vida de las personas". 


\section{CONCLUSIONES}

Tras nueve meses de pandemia, se empiezan a conocer algunos de los efectos económicos y de comercio exterior de las medidas iniciales tomadas por los países para la contención y manejo de la pandemia de la covid-19.

Respecto a las primeras medidas de restricción de exportaciones de equipos médicos, medicamentos e implementos de protección personal, los efectos fueron más leves a lo anticipado. La mayoría de países ya han levantado y flexibilizado sus restricciones y se afectó apenas un $5 \%$ del comercio mundial por poco tiempo. Incluso, estas medidas tuvieron un efecto positivo de agilizar la implementación de mecanismos de facilitación del comercio a través de medios virtuales, en países donde aún no existían estos mecanismos. En suma, naciones, como Estados Unidos o los miembros de la Unión Europea, descubrieron su gran dependencia de China sobre la importación de insumos para la industria farmacéutica, por lo que buscarán diversificar sus proveedores dentro de sus mismas regiones.

Las limitaciones de movilidad y los cierres de frontera tuvieron un grave impacto en el intercambio de bienes y servicios en el mundo. En el caso de los bienes, se incrementaron los costos de transporte y la baja del consumo provocó una caída del $18,5 \%$ del comercio mundial, lo cual se encuentra en el espectro medio de las proyecciones iniciales de la OMC. Por su parte, el comercio de servicios sufrió una grave caída, especialmente en los sectores de turismo y transporte aéreo.

Adicionalmente, el crecimiento de la incertidumbre provocado por la pandemia, ya muestra graves consecuencias en materia de inversión internacional, tal como el retiro de USD 83 billones de IED de América Latina.

Aún no se conocen los efectos a largo plazo que tendrá la emergencia sanitaria, ni los efectos que tendrán las medidas de recuperación económicas que implementen los países en los mercados internacionales. China, particularmente, cuenta con un plan de reactivación económica tan agresivo que tiene el potencial de desencadenar una ola de medidas de defensa comercial en el mundo para contener su expansión.

Las políticas tomadas por China para su reactivación, como el aumento de reembolsos de IVA sobre la exportación de varios productos o el incremento de créditos para empresas exportadoras, que tienen el objetivo de compensar la caída de las exportaciones que tuvo el país en el primer trimestre del año y normalizar su exceso de inventarios, tienen el potencial de distorsionar de manera preocupante los mercados mundiales. Los efectos de estas políticas ya se ven en la industria siderúrgica, donde varios países han tomado medidas anticipadas para proteger sus industrias nacionales.

Las secuelas de la recesión más las políticas chinas de expansión de sus mercados provocarán un aumento en el proteccionismo a través de medidas de defesa comercial y barreras arancelarias y no arancelarias. Lo anterior ya ha sucedido como respuesta en crisis económicas en el pasado.

En Colombia ya se empiezan a evidenciar aumentos en las solicitudes de imposición de medidas de defensa comercial en contra de China, especialmente en el sector de 
construcción e infraestructura que son claves en los planes del Gobierno nacional de recuperación económica del país.

Finalmente, aunque los elementos expuestos en el presente artículo permiten vislumbrar el aumento del proteccionismo en el mundo como resultado de la covid-19, es probable que estos efectos no sean evidentes, sino a partir de 2021 o incluso más adelante.

\section{REFERENCIAS}

Alacero. (2018). 3 cifras clave. América Latina en Cifras, 10-11.

Comisión Económica para América Latina y el Caribe. (2020). Los efectos del COVID-19 en el comercio internacional y la logística. Nueva York: Naciones Unidas.

Delgado, P. (2020, 26 de abril). Cómo la construcción de infraestructura puede reactivar la economía. El Espectador. https://www.elespectador.com/economia/como-la-construccionde-infraestructura-puede-reactivar-la-economia-articulo-916651/

DeloitTE. (2020, marzo). Export VAT refund rates increased on over 1,400 goods. https:// www.taxathand.com/article/13359/China/2020/Export-vat-refund-rates-increased-onover-1400-goods

European Commission. (2020). Commission Implementig Regulation (EU) 2020/894 of 29 June 2020 amending Implementing Regulation (EU) 2019/159 imposing definitive safeguard measures against imports of certain steel products. Official Journal of the European Union, 29-62.

GonZÁlez, A. (2020, 22 de mayo). PIIE Trade Winds: Disruption of Global Value Chains and International Trade Cooperation. https://www.piie.com/events/piie-trade-windsdisruption-global-value-chains-and-international-trade-cooperation

Inside U. S. Trade. (2020a, 12 de agosto). China looks to stabilize trade amid pandemic as purchases fall short. Inside U.S. Trade.

Inside U. S. Trade. (2020b, 6 de agosto). In trade speech, Trump issues six promises, hints at upcoming action. https://insidetrade.com/daily-news/trade-speech-trump-issues-sixpromises-hints-upcoming-action

International Monetary Fund. (2020). World Economic Outlook: The Great Lockdown. Washington D. C.: IMF.

International Trade Centre. (2020, 24 de agosto). Tracking of COVID-19 Temporary Trade Measures. https://www.macmap.org/covid19

Ministerio de Comercio, Industria y Turismo. (2020, 13 de septiembre). Defensa Comercial. https:/www.mincit.gov.co/mincomercioexterior/defensa-comercial

Organización Mundial del Turismo. (2020, 7 de mayo). Las cifras de turistas internacionales podrían caer un 60-80\% en 2020, informa la OMT. https://www.unwto.org/es/news/covid19-las-cifras-de-turistas-internacionales-podrian-caer-un-60-80-en-2020

PlATTS. (2020a). La CE adelanta a principios de mayo la revisión de los aranceles de salvaguardia. Platts.

PLATTS. (2020b). Turkey raises duties on some finished, semi-finished steel products. Platts.

Presidencia de la República. (2020, 30 de julio). Con el plan de reactivación, Colombia sale adelante y sigue siendo un país atractivo para la inversión: Duque. https://id.presidencia. 
gov.co/Paginas/prensa/2020/Con-el-plan-de-reactivacion-Colombia-sale-adelante-ysigue-siendo-un-pais-atractivo-para-la-inversion-Duque-200730.aspx

SERIC, A. y Hauge, J. (2020, 15 de mayo). COVID-19 and the global contraction in FDI. https:// iap.unido.org/articles/covid-19-and-global-contraction-fdi\#fn-340-1

SrivastaVA, S. (2020, 29 de junio). India Plans to Impose Strict Rules and Tariffs on Chinese Imports. https://www.bloombergquint.com/economy-finance/india-is-said-to-weighstrict-rules-tariffs-on-chinese-imports

U. S. Congressional Research Service. (2020). COVID-19: China Medical Supply Chains and Boarder Trade Issues. Washington D. C.: Congressional Research Service Report.

UNCTAD. (2020, 20 de marzo). Impact of the Covid-19 Pandemic on Global FDI and GVCs: Updated Analysis. https://unctad.org/en/PublicationsLibrary/diaeiainf2020d3_en.pdf

World Trade Organization. (2020a). Trade in medical goods in the context of tacklig Covid-19. Ginebra: World Trade Organization.

World Trade Organization. (2020b). Trade costs in the time of global pandemic. Geneva: World Trade Organization.

World Trade Organization. (2020c, 22 de junio). Trade falls steeply in first half of 2020. https:// www.wto.org/spanish/news_s/pres20_s/pr858_s.htm

WTO Integrated Trade Intelligence Portal (I-TIP). (2020, 30 de agosto). I-TIP Goods: Integrated analysis and retrieval of notified non-tariff measures. http://i-tip.wto.org/goods/default. aspx?language $=$ en 